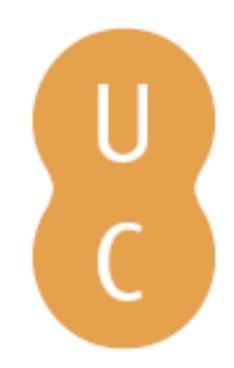

\title{
pompalina
}

\section{New generation of automatic ground based wildfire surveillance systems}

$\begin{array}{ll}\text { Autor(es): } & \text { Stipaniev, Darko; Buggari, Marin; Krstini, Damir; Šeri, Ljiljana; Jakovevi, }\end{array}$

Publicado por: Imprensa da Universidade de Coimbra

URL

persistente: URI:http://hdl.handle.net/10316.2/34230

DOI: $\quad$ DOI:http://dx.doi.org/10.14195/978-989-26-0884-6_160

Accessed : $\quad$ 26-Apr-2023 16:00:50

A navegação consulta e descarregamento dos títulos inseridos nas Bibliotecas Digitais UC Digitalis, UC Pombalina e UC Impactum, pressupõem a aceitação plena e sem reservas dos Termos e Condições de Uso destas Bibliotecas Digitais, disponíveis em https://digitalis.uc.pt/pt-pt/termos.

Conforme exposto nos referidos Termos e Condições de Uso, o descarregamento de títulos de acesso restrito requer uma licença válida de autorização devendo o utilizador aceder ao(s) documento(s) a partir de um endereço de IP da instituição detentora da supramencionada licença.

Ao utilizador é apenas permitido o descarregamento para uso pessoal, pelo que o emprego do(s) título(s) descarregado(s) para outro fim, designadamente comercial, carece de autorização do respetivo autor ou editor da obra.

Na medida em que todas as obras da UC Digitalis se encontram protegidas pelo Código do Direito de Autor e Direitos Conexos e demais legislação aplicável, toda a cópia, parcial ou total, deste documento, nos casos em que é legalmente admitida, deverá conter ou fazer-se acompanhar por este aviso.

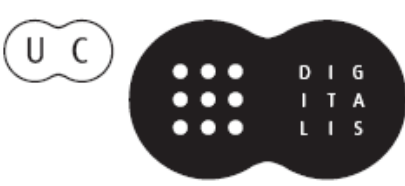




\section{ADVANCES IN}

Forest Fire

\section{RESEARCH}

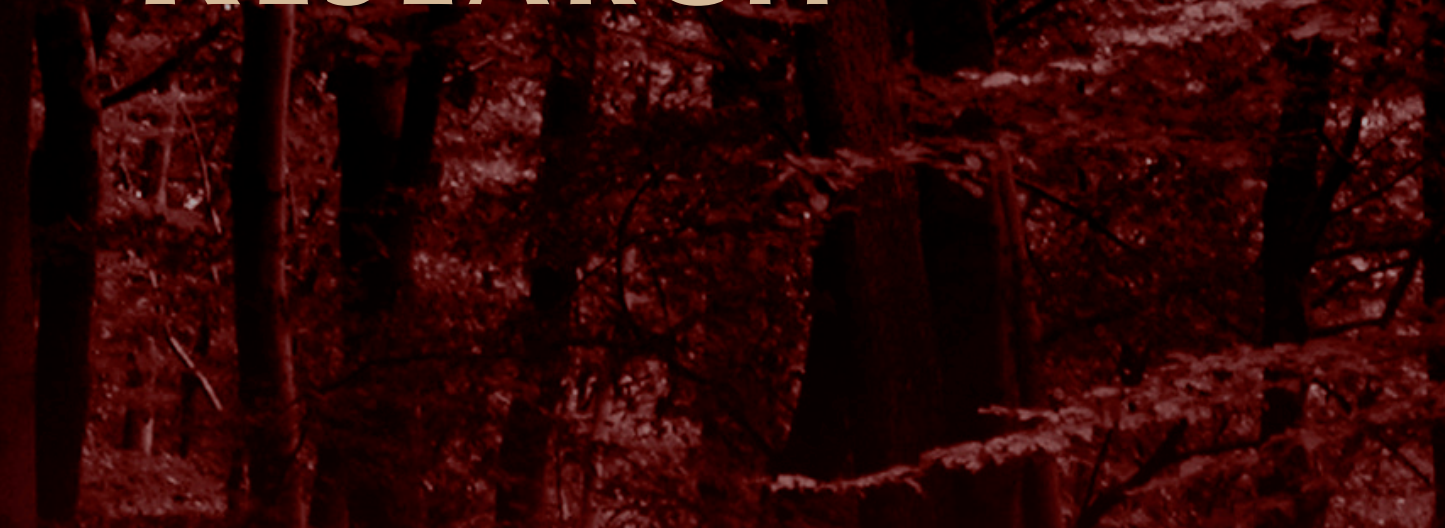

\section{DOMINGOS XAVIER VIEGAS}

\section{EDITOR}




\title{
New generation of automatic ground based wildfire surveillance systems
}

\author{
Darko Stipaničev, Marin Bugarić, Damir Krstinić, Ljiljana Šerić, Toni Jakovčević, Maja Braović, \\ Maja Štula
}

\author{
University of Split Faculty of Electrical Engineering, Mechanical Engineering \\ and Naval Architecture, Department for Modelling and Intelligent Systems \\ Ruđera Boškovića 32, 21000 Split, Croatia.darko.stipanicev@fesb.hr
}

\begin{abstract}
The paper presents a state of the art in the research area of ground based wildfire surveillance systems with special emphasis on their latest generations proposed and developed in the last couple of years. We have focused primarily on novel, more efficient algorithms for wildfire detection, but other topics like fusion of video based systems with other wildfire detection systems and their integration with Geographic Information Systems (GIS) systems has also been analyzed. Our particular focus was on research carried out in our Department. Last but not least, we give our opinions and assumptions about future development of such systems.
\end{abstract}

Keywords: wildfires, forest fires, smoke and fire detection, wildfire monitoring, wildfire surveillance, augmented reality, GIS, wildfire monitoring network, fusion of video data.

\section{Introduction}

Wildfires are still a constant threat to ecological systems, as well as human safety, causing rapid reduction of forest stand. Many efforts in fire prevention and protection are aimed to reduce not only the number of fires, but also the fire damage. It is well known that early fire detection and quick and appropriate intervention are the most important measures for wildfire damage minimization. Once a wildfire has expanded, it is very difficult to control and extinguish. Therefore in countries that have a great wildfire threat, there are a lot of efforts to organize appropriate and efficient wildfire surveillance. Wildfire surveillance 1 is still mostly based on a traditional human wildfire observers, specially trained people located on selected spots with a good visual coverage of protected area, usually equipped only with binoculars, maps and communication units. Their task is to detect wildfire in the incipient stage, try to locate it on the map and to alert the appropriate fire department. In fire season human observers are engaged 24 hours a day and they are exposed to isolation, extreme weather conditions, especially high temperatures and a need for continuous concentration.

Therefore, since 1932 when the inventor called Osborne designed a swing-lens panoramic camera used by USDA Forest Service for wildfire detection (Kresek, 2007), until today a lot of research was done with the aim of photo and video based systems in wildfire detection to make the observers' job less

\footnotetext{
${ }^{1}$ Concerning wildfire observation two terms could be encountered-wildfire surveillance and wildfire monitoring. They are often thought as synonymous, but there is a certain difference in their meaning and a lot of discussions about these differences. More or less in all discussions people agree that they are identical in the fact that they collect routinely information on phenomena, but surveillance is more than monitoring. Under surveillance the information collected are analyzed, interpreted and action taken while in monitoring the action might not necessarilly be there, depending on the purpose of this monitoring. The other difference is that term surveillance is mostly used when information is collected primarily by vision sensors, and in monitoring it is not necessary to have a vision sensor at all and instead any other kind of sensors could be used. As our focus is primarily on vision based systems in this paper we will use the term wildfire surveillance.
} 
strenuous and easier. These research efforts were particularly intensive after 80s, thanks to development of video technology. At the beginning, that was only dislocation of the observer to the observation center and installment of pan, tilt, zoom controlled video cameras on monitoring spots, but quite soon more advanced systems have been proposed with the ability of automatic wildfire detection (Cappellini et al., 1989). Human observer no longer needs to constantly look at the monitor. His/her job is now to check and verify whether the raised alarm is real or false. Such automatic systems could be used not only for early fire detection, but also for distant video presence, a task very important for preventive inspection of the protected area as well as for fire-fighting coordination when the fire starts, so they are usually called automatic wildfire surveillance systems and to emphasize that they are located on the ground automatic ground based wildfire surveillance systems.

Since the end of the 80s, a few generations of such systems have been developed, designed and deployed, not only as experimental, but also as real working systems (Kührt, 2001) (Dedeoglu et al., 2005) (De Dios et al., 2008) (Stipaničev et al., 2010). Improvements have occurred on different parts and functions, both on hardware and software level. This paper focuses on the last generation of such systems that have been proposed in the last couple of years. Our attention is particularly focused on:

a) Algorithms for wildfire smoke and fire detection, resulting in significant improvement of detection features,

b) Fusion of video detection in various electromagnetic ranges, as well as fusion of video detections with other sensor types,

c) Close integration of wildfire surveillance and monitoring and systems with Geographic Information Systems (GIS), resulting in new features in both fire detection and distant video presence modes,

d) Synergy effect of wildfire observer network consisting of mutually connected individual wildfire observers working together in cooperation.

The paper presents a state of the art in this research area with emphasis on the research carried out in our Department in the last couple of years (Stipaničev et al., 2010) (Šerić et al., 2011) (Jakovčević et al., 2013) (Bugarić et al., 2014). We have worked and we are working on almost all of the topics listed above, both on the experimental, laboratory level but also on practical implementation.

\section{Improvements in algorithms for wildfire smoke and fire detection, resulting in significant improvement of detection features}

Vision based wildfire detection systems are mainly focused on smoke detection during the day and fire detection during the night. Since 80s, a lot of different algorithms have been proposed based on different smoke and fire visual characteristics. In this review we have been focused on recent works since 2011. Review of the previous works in this field could be found in (Jakovčević et al., 2011).

Most of the methods for smoke detection are based on the moving region detection as the first step of the detection process. Ashish at al. proposes an algorithm (Ashish et al., 2013) based on the background subtraction method introduced by Collins at al. (Collins et al., 1999). In detected regions, color is used as discriminatory characteristic where smokes colored pixels are expected to have small aberration in red, green and blue channels from the average value of all three channels. Another distinctive characteristic of smoke is perimeter to area ratio that is expected to be above the predefined threshold. Finally, suspicious regions that satisfy above given conditions are checked against dynamic property of the smoke that it continuously moves in upward direction. Brovko et al. (Brovko et al., 2013) proposed an algorithm based on motion and contrast, with wavelet transform applied as a preprocessing step to reduce the image size and to remove high frequencies details. Slowly moving areas are detected by frame differencing of 3 consecutive frames. Model for blending semitransparent objects with background is introduced with: 


$$
I_{t+1}(x, y)=x F_{t+1}(x, y)+(1 \quad) \times B_{t}(x, y)
$$

where $I_{t+1}(x, y)$ is the current frame, $\beta$ is the blending parameter and $B_{t}(x, y)$ is the background from the previous step. As soon as frame $I_{t+1}(x, y)$ is obtained, foreground can be estimated from equation (1). Smoke propagation direction based on optical flow calculation is used as a final test for suspicious regions.

Complex wildfire smoke detection technique is proposed by Labati et al. (Labati et al., 2013) based on the previous work by Genovese et al. (Genovese et al., 2011) using computational intelligence methods to dynamically adapt to the environment. Proposed algorithm can be summarized in the following steps: moving region detection, smoke-color analysis, sharp edge detection, growing region detection, rising region detection, perimeter disorder analysis and feature set computation. Moving region detection is based on the work of Collins et al. (Collins et al., 1999). Two different background images are estimated. The first one is updated at every frame and the second is updated with a period of 1 second. Two background images are used to extract slow moving regions. A matrix $D_{M}$ representing the motion of every pixel is computed according to:

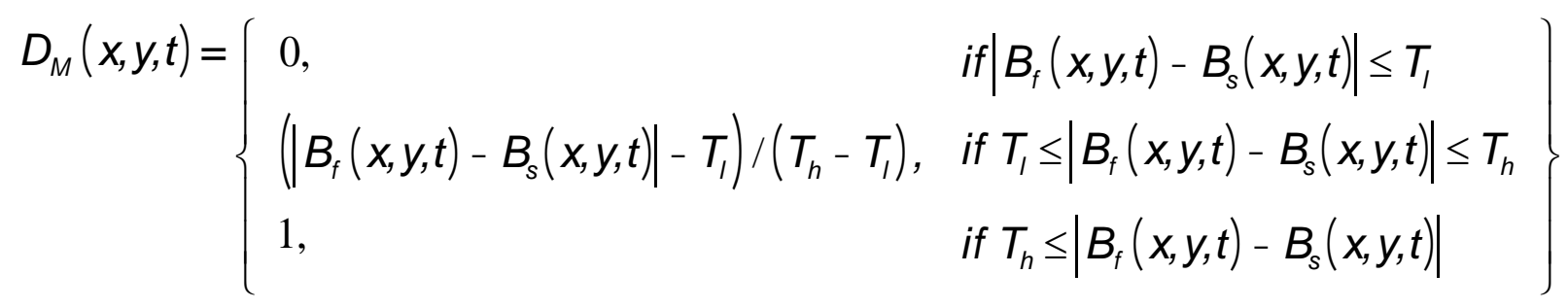

where $0<T_{l}<T_{h}$ are fixed threshold values. In the next step color feature matrix is computed based on the work of (Toreyin et al., 2009) and pixels not satisfying predefined conditions are discarded. Sharp edge detection step aims to search high differences in the luma channel of adjacent frames, usually not present in the regions containing smoke. Growing region matrix is computed as the difference between the moving regions at the time instants $t$ and $t-l$ and only positive values of growth are considered to avoid excessive data fluctuations. Finally, rising value of the moving pixel and the perimeter disorder is computed. Two different algorithms use the computed features set. In Algorithm $A$ the features are extracted for every pixel of each frame of the frame sequence and in Algorithm $B$ the features are extracted globally for each frame. Feature selection algorithm based on kNN is applied separately for different scenarios. Obtained features are used as inputs for computational intelligence and statistical classifiers.

Park et al. (Park et al., 2013) proposed an algorithm for wildfire smoke detection using spatialtemporal bag-of-features (BOF) technique. Slow moving regions are extracted by key-frame detection, followed by rejection of non-smoke colored blocks based on probability density function of smoke color model learned from the training data. For the remaining suspicious blocks, combining the candidate blocks with 100 corresponding blocks in previous frames creates a spatial-temporal 3D volume. Histogram of optical flow (HOF) is extracted as a temporal feature and histogram of gradients (HOG) extracted from the current block is used as a spatial feature. Random forest classifier trained from the training data is used as a final confirmation of smoke.

Vipin (Vipin, 2012) proposed a rule-based system for forest fire detection. Fire-colored regions are detected by processing input images in $\mathrm{RGB}$ and $\mathrm{YCbCr}$ color spaces. Avgerinakis et al. (Avgerinakis, 2012) proposed an algorithm based on temporal HOGHOF descriptors and color energy. Separation of moving from static pixels is based on the assumption that real motion introduces deviation from the Gaussian distribution of motion vector induced by noise. Moving blocks are constructed in regions 
where at least $50 \%$ of pixels are detected as moving. HOG descriptors are calculated for moving blocks and HOF is constructed from previous set of frames. Extracted HOG and HOF descriptors from the training set are used to train SVM classifier. When a frame with smoke is detected, second stage of the algorithm takes place, where statistics based on the color energy of the candidate blocks are analyzed to determine whether they contain smoke or not.

Algorithm proposed by Lee et al. (Lee et al., 2012) is based on hybrid motion segmentation using frame differencing and Gaussian mixture model. For the regions with detected motion spatial and temporal features are extracted. Spatial wavelet analysis detects loss of energy in high frequencies is followed by temporal energy analysis differencing sudden loss of energy corresponding to rigid objects from the gradual loss of energy which may represent smoke. Color information is used as the third characteristics for identifying smoke in a video. Based on the empirical analysis, authors assume that smoke affects every component in the RGB color space. However, it does not drastically change the configuration of the normalized rgb color system. Described features extracted from the training data set are combined and used to train SVM classifier. Final verification of the smoke is based on temporal consistency. The alarm is raised if smoke is detected for over $50 \%$ of a predefined time interval. In the study presented by Ko et al. (Ko et al., 2012) moving regions are detected using key-frame differencing. Features extracted from the training data are used to train two random forest (RF) classifiers. One is trained using temporal features, namely: average hue, saturation, intensity and skewness of the hue, average wavelet energy and skewness of the wavelet energy and spatial motion orientation from the preceding 100 frames. Histogram of gradients (HOG) from the current block is used to train the other classifier. A candidate block is declared as smoke block if the average probability of two RF classifiers in a smoke class is maximum.

Surit and Chatwiriya (Surit, 2011) proposed a technique based on frame differencing. Moving blocks are examined and confirmed as smoke based on color. Habiboglu et al. (Habiboglu et al., 2011) proposed an algorithm based on two background models, where one is optimized to detect fast moving objects used to differentiate ordinary objects from smoke-like moving regions. Set of thresholds in YUV color space is used to further filter non-smoke from smoke colored pixels. Slow moving region detection was based on GMM background models. Background model optimized to detect fast moving objects is used to differentiate ordinary objects from smoke-like moving regions. Set of thresholds in YUV color space is used to further filter non-smoke from smoke colored pixels. For each pixel satisfying the color condition a set of covariance descriptors is extracted, including luminance, chrominance, intensity and its temporal derivatives. The video is divided into blocks that do not overlap in spatial domain but there is $50 \%$ overlap in time domain. SVM classifier is trained for classification. Similar technique based on the covariance descriptors and SVM classification was also proposed for flame detection (Habiboglu et al., 2012).

Last but not least let us mention the work of our Department concerning improved algorithms for wildfire smoke detection. Interesting and promising research work was integration of context information in wildfire detection, together with motion, chromatic, texture and shape analysis (Jakovčević et al., 2011). Visual context analysis was performed by region merging segmentation, classification and applying context rules based on shape analysis. The phase of classification into classes smoke, low clouds and fog, sun and light effects, water surface and sky, distance landscape and vegetation, was not used for detection itself, but as a validation process for false alarms reduction. Fig 1 shows an example of input and classified image. 

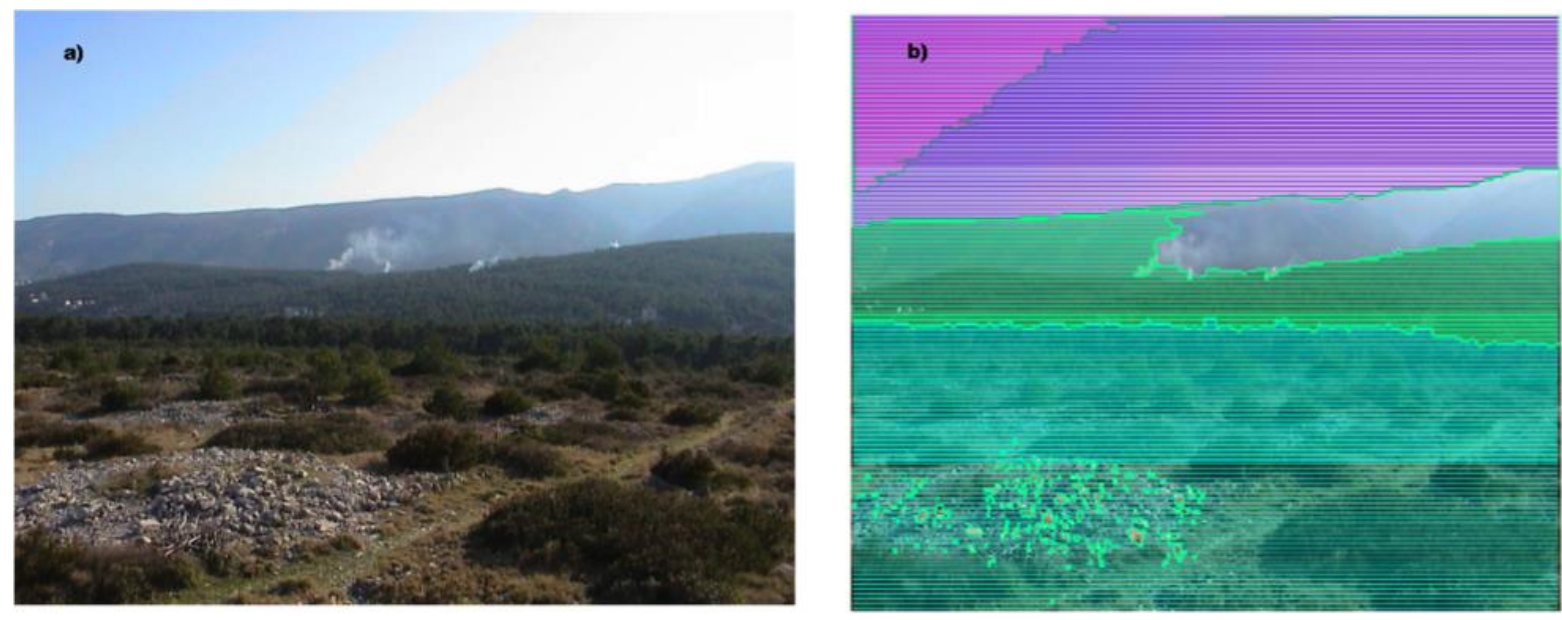

Figure 1. a) Input image and b) classified image used in visual context analysis

\section{Fusion of video detection in various electromagnetic ranges and fusion of video detections with other sensor types}

Sensory data fusion is today one of the top themes in artificial perception inspired by human perception. Humans usually use the fusion of data from more than one sensor in order to understand their surroundings. Usually the fusion processes are divided in low level or data fusion, intermediate level or feature fusion and high level or decision fusion (FireSense, 2010). Low level fusion or data fusion combines various raw data to produce new raw data having additional information in comparison with input data. Intermediate fusion or feature fusion is a fusion of features primarily extracted from row data. High level fusion or decision fusion is performed on the decision making level when various sources are used only for final decision making. In wildfire surveillance all three fusion types could be used and realized as fusion of video data captured in various electromagnetic ranges, usually visible and IR spectra and fusion of video data with other sensors data, particularly meteorological sensors data. Fig 2 shows an example of smoke visibility during typical hot summer day in visible and far IR spectra.

The research presented in (Verstockt et al., 2012) describes a multi-sensor approach to smoke detection using visible and thermal imaging. The information from both sensors is analyzed in order to extract moving objects that could potentially represent smoke. The silhouette of the moving objects is examined in order to determine the appearance of smoke in the scene. In order to implement this type of multi-sensor detection process, images for two different sources have to be registered. The registration is performed using a contour-mapping algorithm where the rotation, scale and translation of moving objects are discovered. 

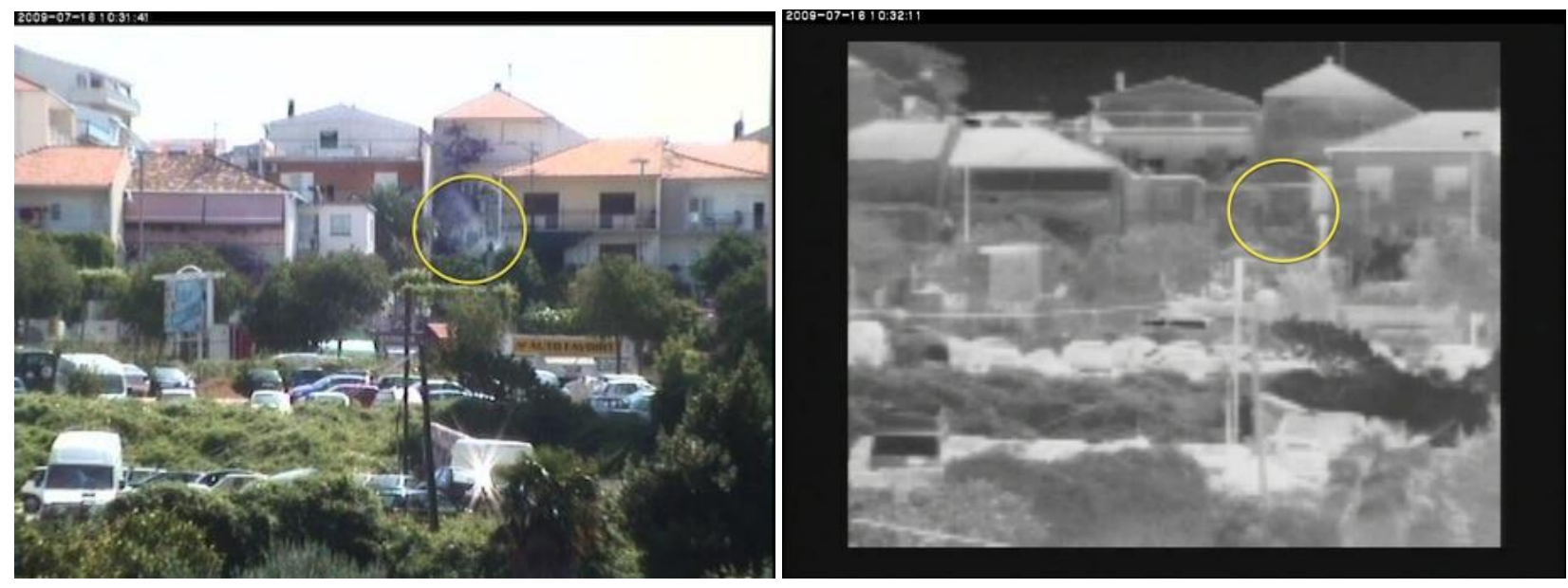

Figure 2. Smoke visibility during typical hot summer day in visible spectra (left) and far IR spectra (right)

Another approach, presented in (Torabnezhad et al., 2013), describes a new method of smoke detection based on fusion of information from IR and visible sensors, since each source alone cannot provide the full information about the potential event. The method is designed for smoke detection on short distances. The smoke is not visible in the IR images, so this feature is used to distinguish between smoke and objects/phenomena visually similar to smoke. The method consists of two phases. In the first phase the input from both sources is used to generate a potential-smoke mask. The mask from the visual source is obtained using background subtraction and a smoke color model, while the mask from the IR source is obtained using hot object segmentation where due to invisibility of smoke in the IR image the smoke pixels are not segmented as hot objects. The potential smoke mask is built using these two masks as input. The second step is based on disorder measurements and energy calculation in order to reduce false alarms. The authors characterize the method as very effective and accurate.

Work presented in (Verstockt et al., 2010) describes a new multi-sensor fire detection system operating on ordinary video and long wave infrared (LWIR) thermal images. The detection process consists of several phases. When dealing with thermal images, the detector extracts hot objects using dynamic background subtraction and histogram based segmentation. Similarly, when dealing with ordinary video, moving objects are extracted using dynamic background subtraction. Both types of objects, hot and moving, are further analyzed using flame features based on specific geometric, temporal and spatial disorder characteristics of flame regions. By combining probabilities of visual and thermal features, according to authors it is possible to detect fire at an early stage.

Salah et al. (Salah et al., 2011) describes an FP7 project dealing with protection of cultural heritage sites from the risk of fire and extreme weather conditions. The fire protection is provided using a fusion of information obtained from IR and visible images. The main problem with this type of approach is the image registration between two different sources. The objective is to discover the correspondences between images. When the correspondences have been found the images can be transformed into the same reference so it is possible to achieve information fusion. The process of registration is challenging because the wavelengths of the IR and visible spectrum are different, so the general approaches such as SIFT and RANSAC do not work properly in this case. Authors have discussed several different registration approaches and proposed explicit alignment of lines derived from edge pixels. The individual extracted points could not always match correctly, so a Hough transform is used to generate lines. Using four of the generated lines it is possible to obtain perspective transformation matrix used for registration. The paper does not present explicit results for the fire detection process.

Although detection of wildfires using fusion of video data is most common, there are some drawbacks to this approach, primarily fusion of video based systems and other sensor types. Various types of sensors are used in wildfire detection, primarily meteorological sensors like temperature, pressure, humidity, wind and sun radiation sensors, but chemical sensors sensing carbon monoxide, carbon 
dioxide and nitrogen dioxide are also used. The main problem in video - sensors data fusion is the correct fusion application for heterogeneous sensor types. Interesting example of smoke video detection and meteorological information fusion were presented by Štula et al. (Štula et al., 2011) where fuzzy cognitive maps with 4 concepts: current wind, conclusion on alarm (true/false), false alarms generated in the last 24 hours and current humidity was used for false alarms reduction in image post-processing phase.

Fire detection on Wild-land Urban Interface (WUI) using wireless sensor network was studied in SCIER project (Sekkas et al., 2010). The system architecture consists of three layers: Sensors, Local Area Control Unit (LACU) and Computing Subsystem. Sensors that are measuring temperature, humidity and vision sensors are organized into local clusters. LACU is responsible for administration of local sensor network. First level of fusion is performed on local cluster by calculating cumulative sum (CUSUM test) of local sensors and assigning basic probability of fire to each of them. Computing subsystem perform second level of fusion. Data from all LACU units are fused using Dumpster-Shafer evidential theory.

In (Šerić et al., 2011) authors proposed framework for multi sensor data fusion based on vision sensor and environmental sensors with goal of forest fire detection and false alarm reduction. The framework utilizes formal theory of perception and describes data fusion aiming to detect sensors and network failure (syntactic and semantic data validation) and occurrence of wildfire phenomenon. The system is also interesting, because it is entirely based on software agent's architecture. Software agents and intelligent software agents are responsible for everything from image and data collection to final wildfire recognition.

\section{Integration of wildfire surveillance and monitoring systems with GIS}

GIS can be of great benefit for wildfire surveillance, regardless of whether it is used in the phase before, during or after the wildfire (pre-fire, fire and post-fire). Geographic position of wildfire, as well as the time of ignition, is of vital importance in many aspects of human and material safety. In the 'pre-fire phase' GIS could be used to calculate the probability of fire occurrence. Wildfire risk index is a numerical indicator that defines the level of fire risk and as such is associated with a certain geographic area. For this reason, GIS is the right tool that could be used to develop advanced wildfire risk models. We have developed a site-specific wildfire risk index (SWRI) that is focused on the microlocation and based on climatological and meteorological parameters, vegetation, terrain configuration and anthropogenic parameters (Bugarić et al., 2014).

SWRI could be quite useful in wildfire surveillance systems, particularly in its automatic mode for more successful wildfire detection. An example is recent work of Bugarić et al. (Bugarić et al., 2014) where it was shown how any existing smoke detection methods could be improved by the automatic adaptation of smoke detection parameters based on SWRI. Almost every existing smoke detection method depends on various detection parameters that could be manually edited and change to adapt the algorithm and particularly its sensitivity, on the current weather situation. Normally this is a job of system operators, but in practice we could encounter that operators are not very keen to interact with detection procedure and change parameters. One of the possible solutions is automatic adaptation of smoke detection parameters. In our approach it was based on GIS and Augmented Reality (AR). GIS was used for calculation of SWRI and augmented reality scene calibration. The idea was to find link between real world scene and digital elevation model based on GIS. Then the calculated SWRI map in GIS could be transformed to word scene as Fig 3 shows and applied for adaptation of detection parameters. On all those image parts where fire risk index is high the detection algorithm sensitivity will be also higher and vice versa where there is small fire risk index, for example on river parts the algorithm sensitivity could be lowered to zero. 

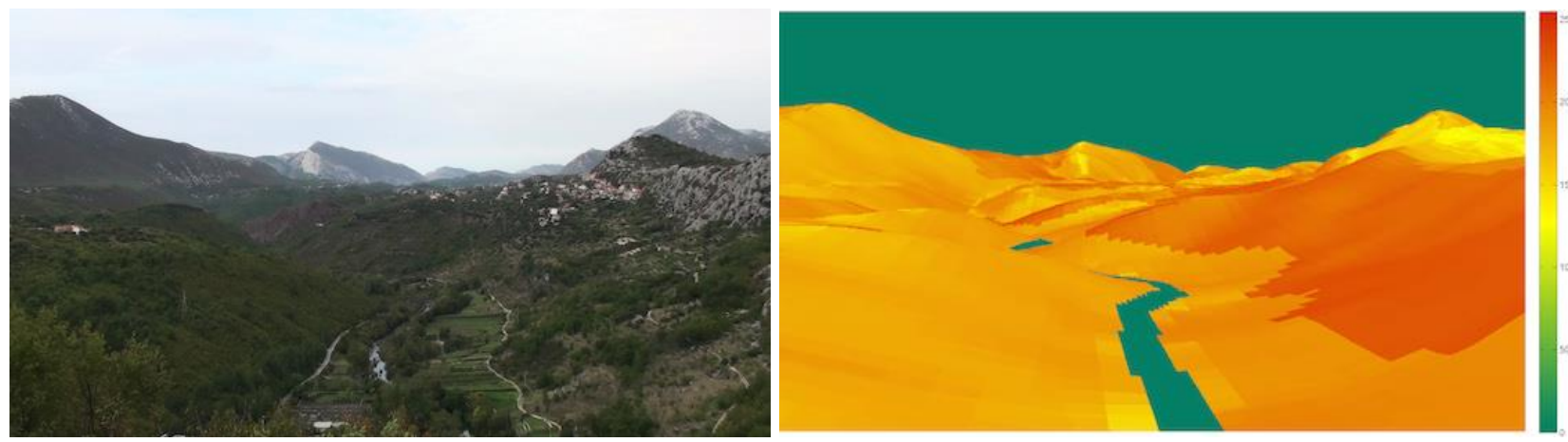

Figure 3. Original image of detection area and synthetic AR image of the same view with superimposed site-specific wildfire risk index

Augmented Reality based mixing of real images and GIS produced data could be used not only for automatic adjustment of motion detection sensitivity, but also to selective blurring of input images based on point distance from the camera, definition of the minimal candidate region size and dynamics analysis based on detected region growth.

Augmented reality in combination with GIS could be useful in manual mode of wildfire surveillance and monitoring systems as well. The important fact is that these systems are geo-referenced, so for every pixel in the image the corresponding geo-coordinate is known and vice versa. Therefore, in manual mode, relevant GIS information such as toponyms, compass, geographic coordinates or altitudes could be presented on a real-time video stream. Another important capability of GIS, useful in the phase before the wildfire, is interpreting and visualizing the current weather conditions, such as wind speed and direction, temperature or humidity. These data could be of great importance in the case of organizing fire-fighting activities. Figure $4 \mathrm{a}$ shows an example of dynamic presentation of meteorological data where weather information is automatically and dynamically retrieved from a Croatian Meteorological and Hydrological weather server several times a day. Important is to note that this feature is of equal importance also in the fire phase when it is important to predict the future fire behavior.

Visibility of any point manually chosen on the map could be easily verified using simple trigonometry and Digital Elevation Models. Note that visibility maps and elevation profiles could also be generated using GIS, as this feature is suitable for better understanding of what is visible in the camera image. Another important feature that GIS systems provide is the determination of azimuth, elevation and field of view of the actual video camera viewing as Fig $4 \mathrm{~b}$ shows.

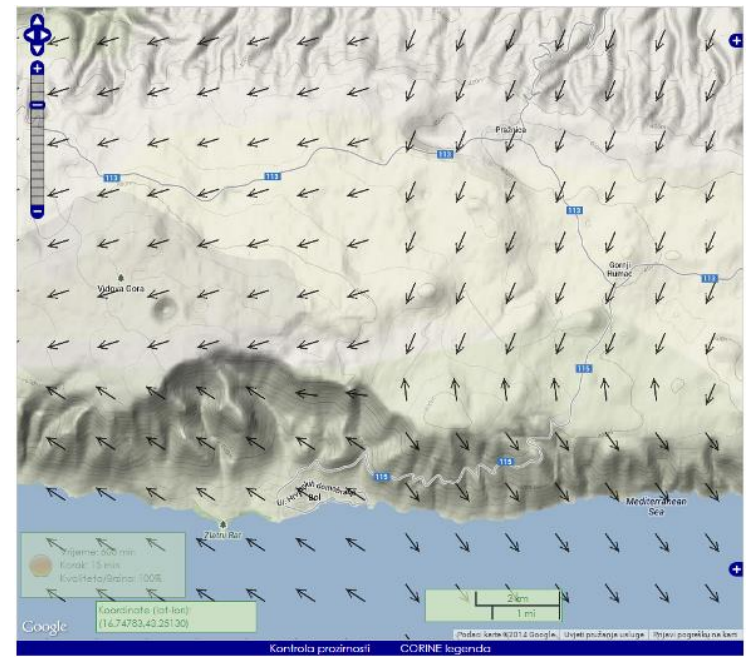

(a)

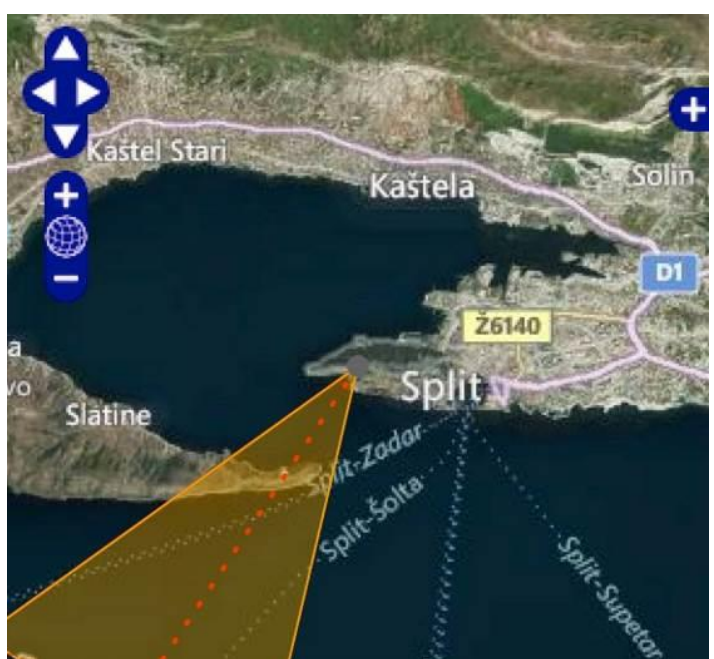

(b)

Figure 4. a) Superposition of dynamic meteorological data on GIS maps and b) presentation of cameras azimuth and field of view on GIS map 
When wildfire is spotted the 'fire phase' start. For wildfire damage minimization it is important to have a rapid and well-organized response. Apart from the information concerning the current weather conditions, knowledge about the wildfire features is equally important as it may affect the final outcome. These features include the time and geographic coordinates of the ignition, the way in which the wildfire spreads, real-time tracking of the fire front and the current location of fire-fighting units in the field.

After a successful detection of the wildfire, determining the ignition point and displaying it on the map could be done using 'alidade'-like devices such as Osborne Fire Finder or DragonPlot (Guth et.al., 2005). However, more advanced methods using vision based wildfire surveillance and GIS could be used. Almost all wildfire surveillance systems on the market have this ability, either as cameras azimuth ray intersection with digital elevation model, triangulation if few cameras could see the fire location or based as afore mentioned AR systems that we have developed (Bugarić et al., 2014). It has the ability to extract geographic coordinates by simply clicking on any pixel on real life image using AR based pre-calculated image templates where for every image pixel its corresponding lat-longheight coordinate is determined.

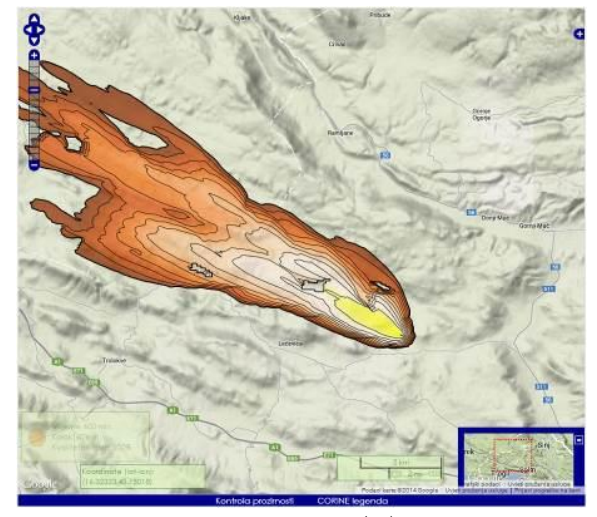

(a)

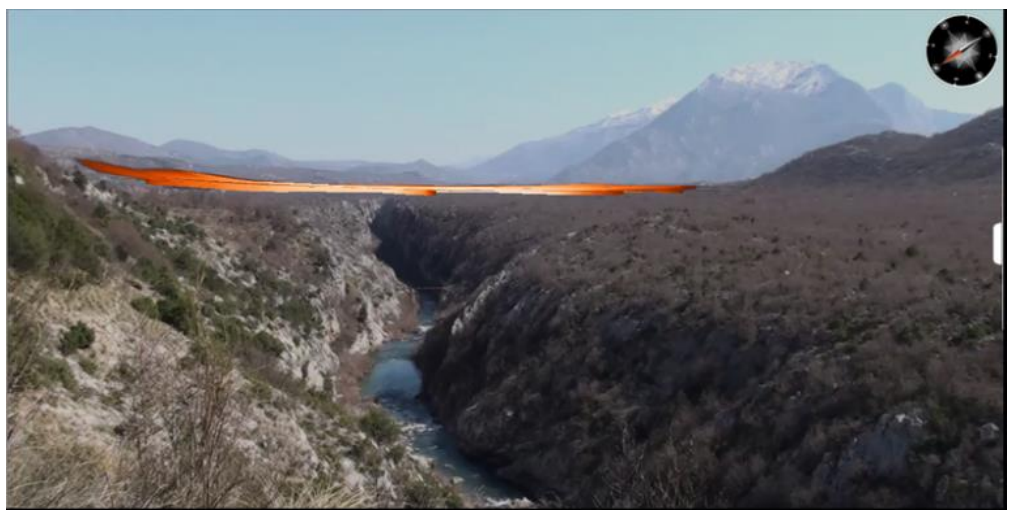

(b)

Figure 5. a) Simulated wildfire spread shown on GIS map and b) superimposed in real time on real camera view using Augmented Reality methods

Wildfire propagation modeling and simulation is another feature for wildfire surveillance, useful in pre-fire and fire phase. Based on vegetation characteristics, landscape and meteorological conditions the future fire spread could be simulated in appropriate time steps. Fig 5a shows result on one such simulation for SE winds. In pre-fire phase it could be used for training and in fire phase for proper intervention planning and management. Augmented Reality could be used for superposition of fire spread simulation results on real life image as Fig 5 b shows.

\section{Synergy in wildfire observance networks}

Aristotle coined that "The whole is more than the sum of its parts." This sentence was later used to describe the synergy, the effect that exists between parts of a system working together in a cooperative effort. Therefore, having a wildfire observance network of mutually connected individual wildfire observers working together in cooperation, could give the overall effect greater than the sum of their individual effects. Cooperation of individual wildfire observers could be used to improve automatic wildfire detection as well as to enhance manual camera PTZ control.

Let us suppose that we have a region covered by a network of wildfire observers and that certain part could be seen from three different observation points. The biggest problem in visual wildfire detection is still rather high false alarms rate, so any effort in order to minimize false alarm rate is welcomed. A 
network of wildfire observers could be used for that, because it is unlikely to have a false alarm on the same location on all three observers units. If observers exchange information about alarms and their estimated locations a simple procedure could be used for additional false alarms reduction.

Also using the wildfire observer network the manual PTZ cameras control could be improved and simplified. An example is 'one click multiple cameras control' principle (Stipaničev et.al., 2009), (Stipaničev et al., 2011). One click means that all cameras covering the same region could be controlled by simple click on the map. The system automatically calculate the target point visibility from various observation points and appropriate cameras pan and tilt movements for all those cameras that could see the selected location.

\section{Conclusion}

In the future we could expect more and more wildfires, therefore in countries where wildfire risk is high, a lot of time and money is spent to minimize the wildfire effects. Maybe it is difficult to drastically reduce the number of fire ignitions, but the damage could be minimized by early wildfire detection and quick and appropriate intervention. Early wildfire detection is usually organized as a wildfire surveillance service and today this service is more and more based on application of modern ICT technologies, particularly new sensors, processing units, algorithms and calculation procedures. In this paper our focus was on automatic wildfire surveillance systems. They have evolved a lot in the last few years. More and more sophisticated algorithms for wildfire smoke and fire detection were developed, fusion of video detection in various electromagnetic ranges and fusion of video detections with other sensor types are today used, as well as close integration of wildfire surveillance and monitoring and systems with GIS, resulting in new features in both fire detection and distant video presence modes. Last but not least we have discussed a synergy effect of wildfire observer network consisting of mutually connected individual wildfire observers working together in cooperation. Although a lot of new wildfire surveillance systems has been developed and applied in various regions our opinion is that in the future we should expect even greater achievements in automatic wildfire surveillance systems development and implementation. Today human wildfire observers are still dominant (Matthews et al., 2010), but we are sure that high definition cameras, more advanced algorithms and powerful processing engines will improve automatic wildfire detection and reduce the difference between human and machine wildfire detection.

\section{References}

Ashi et al., 2013 Ashish A., Narwade, V., Chakkarwar, A. "Smoke Detection in Video for Early Warning Using Static and Dynamic Features." Int. Journal of Research in Eng and Tech. 02, no. 11: 610-614. 2013

Avgerinakis et al., 2012 Avgerinakis, K., Briassouli, A., Kompatsiaris, I. "Smoke Detection Using Temporal HOGHOF Descriptors and Energy Colour Statisrics from Video." Proc. of the Int.l Workshop on Multi-Sensor Systems and Networks for Fire Detection and Management. Antalya, Turkey, 2012

Brovko et al., 2013 Brovko, N., Bogush, R., Ablameyko, S. "moke detection algorithm for intelligent video surveillance system." Computer Science Journal of Moldova 21, no. 161) 2013): 142-156.

Bugarić et al., 2014 Bugarić, M., Jakovčević, T., D. Stipaničev, D. "Adaptive estimation of visual smoke detection parameters based on spatial data and fire risk index ." Computer Vision and Image Understanding 118 (2014): 184-196.

Bugarić et al., 2009 Bugarić, M., Jakovčević, T., D. Stipaničev, D. "Automatic Adjustment of Detection parameters in Forest Fire Video Monitoring System," 32nd Int. Conf. MIPRO 2009. Opatija, 270-275. 
Bugarić et al., 2013 Bugarić, M., Braović, M., Stipaničev, D. "Augmented reality based segmentation of outdoor landscape images,", Sept 2013, pp. 43-48." 8th International Symposium on in Image and Signal Processing and Analysis (ISPA). 2013. 43-48.

Bugarić et al., 2014 Bugarić, M., Stipaničev, D., Šeric, Lj. "Statistical evaluation of micro-location wildfire risk index calculation for Adriatic regions." VII Int. Conference on Forest Fire Research. Coimbra, 2014.

Cappelini et al., 1989 Cappellini, V., Mattii, L., Mecocci, A. "An intelligent system for automatic fire detection in forests." Third Int. Conference on Image Processing and its Applications. 1989. 563 570.

Collins Bugarić et al., 1999 Collins, R. T., Lipton, A. J., Kanade, T. "A System for Video Surveillance and Monitoring." 8th Int. Topical Meeting on Robotics and Remote Systems. Pisttsburgh, 1999.

De Dios et al., 2008 De Dios, J.R.M., Arrue, B.C., Ollero, A., Merino, L., Gómez- Rodríguez, F. "Computer vision techniques for forest fire perception." 26, no. 4 2008: 550-562.

Dedeoglu et al., 2005 Dedeoglu, Y., Töreyin, B., Güdükbay, U., Çetin, A.E. "Real-time fire and flame detection in video." Proc. of IEEE Int. Conf. on Acoustics, Speech, and Signal Processing. Phil, 669-672.

FireSense, 2010 Del.No.D4 - "Preliminary Report on User Requirements Identification and Analysis", FireSense Project, 2010, http://www.firesense.eu/ .

Genovese et al., 2011 Genovese, A., Labati, R.D. Piuri, V., Scotti, F. "Wildfire Smoke Detection Using Computational Intelligence Techniques." IEEE International Conference on Computational Intelligence for Measurement Systems and Applications (CIMSA 2011),. Ottawa, Canada, 2011. 16.

Guth et al., 2005 Guth, P.L., Vraven, T., Chester, T., O'Leary, Z., Shotwell, J. "Fire location from a single Osborne Firefinder and DEM." ASPRS 2005 Annual Conference Geospatial Goes Global: From Your Neighborhood to the Whole Planet. Baltimore, 2005.

Habiboglu et al., 2012 Habiboglu, Y. H., Gunay, O., Cetin, A. E. "Covariance matrix-based fire and flame detection method in video." Machine Vision and Applications 23, no. 6 (2012.): 1103-1113.

Habiboglu et al., 2011 Habiboglu, Y. H., Gunay, O., Cetin, A. E. "Real-Time Wildfire Detection Using Correlation Descriptors." European Signal Processing Conference. Barcelona, Spain, 2011.

Jakovčević et al., 2011 Jakovčević, T., Braović, M., Stipaničev, D., Krstinić, D. "Review of Wildfire Smoke Detection Techniques based on Visible Spectrum Video Analysis." Proc. of International Symposium on Image and Signal Processing and Analysis. Dubrovnik, Croatia, 2011. 480-484.

Jakovčević et al., 2011 Jakovčević, T., Stipaničev, D., Krstinić, D. "Visual context-based forest-fire smoke sensor." Machine Vision and Applications 24, no. 4 2013: 707-719.

Kührt et al., 2001 Kührt, E., Knollenberg, J., Mertens, V. "An automatic early warning system for forest fires." Ann. Burns Fire Disasters 14, no. 3 2001: 151-154.

Ko et al., 2001 Ko, B., Kwak, J., Nam, J. "Wildfire smoke detection using temporspatial features and random forest classifiers." Optical Engineering 51, no. 12012.

Kresek, 2007 Kresek, Ray. "History of the Osborne Firefinder ." 2007. http://www.nysforestrangers.com/archives/osborne\%20firefinder\%20by\%20kresek.pdf .

Labati et al., 2013 Labati, R.D., Genovese, A., Piuri, V., Scotti, F. "Wildfire Smoke Detection using Computational Intelligence Techniques Enhanced with Syntetic Smoke plume Generation." IEEE Trans. on Systems, Man, and Cybernetics 43, no. 4 2013: 1003-1012.

Lee et al., 2012 Lee, C., Lin, C., Hong, C., Su, M. "Smoke Detection Using Spatial and Temporal Analyses." int. Journal of Inovative Computing, Information and Control 8, no. 72012.

Matthews et al., 2010 Matthews, S., Sullivan, A., Gould, J., Hurlay, R., Ellis, P., Larmour, J. "Evaluation of three fire detection systems." Bushfire Cooperative Research Center, Canberra, 2010, 82 . 
Park et al., 2013 Park, J., Ko, B., Nam, J. "Wildfire Smoke Detection Using Spatio Temporal Bag-ofFeatures of Smoke." IEEE Workshop on Appl. of Computer Vision (WACV 2013). Clearwater Beach, FL, USA, 2013.

Salah et al., 2011 Salah A. A., Han J., Pauwels E., de Zeeuw P. "Multimodal Monitoring of Cultural Heritage Sites and the FIRESENSE Project." Proceedings of the 4th International Symposium on Applied Sciences in Biomedical and Communication Technologies. 2011. 152:1-152-5.

Sekkas et al., 2010 Sekkas, O., Hadjiefthymiades, S., Zervas, E. "A Multi-level Data Fusion Approach for Early Fire Detection." Proceedings of the 2010 International Conference on Intelligent Networking and Collaborative Systems INCOS '10. Washington, 2010. 479-483.

Stipaničev et al., 2009 Stipaničev, D., Bugarić, M., Bodrožić, Lj. "Integration of Forest Fire Video Monitoring System and Geographic Information System ." Proc. of 51st Int. Symp. ELMAR 2009. Zadar, 2009. 49-52.

Stipaničev et al., 2010 Stipaničev, D., Štula, M., Krstinić, D., Šerić, Lj. jakovčević, T. M.Bugarić,. "Advanced automatic wildfire surveillance and monitoring network." VI International Conference on Forest Fire Research. Coimbra, 2010.

Stipaničev et al., 2011 Stipaničev, D., Bugarić, M., Šeric, Lj., Jakovčević, T. "Web GIS Technologies in Advanced Cloud Computing Based Wildfire Monitoring System." 5th International Wildland Fire Conference WILDFIRE 2011. Sun City, 2011.

Surit et al., 2011 Surit, S., Chatwiriya, W. "Forest Fire Smoke Detection in Video Based on Digital Image Processing Approach with Static and Dynamic Characteristics Analysis." First ACIS/JNU International Conference on Computers, Networks, Systems and Industrial Engineering CNSI, 2011.

Šerić et al., 2011 Šerić, Lj., Stipaničev, D., Štula, M. "Observer network and forest fire detection." Information Fusion 12, no. 3 2011: 160-175.

Štula et al., 2011 Štula, M., Stipaničev, D., Šerić, Lj., Krstinić, D. "Fuzzy Cognitive Map for decision support in image post-processing." Proc. of IWSSIP 2011. Sarajevo, 2011. 311-314.

Torabnezhad et al., 2013 Torabnezhad M., Aghagolzadeh A., HadiSeyedarabi H. "Visible and IR image fusion algorithm for short range smoke detection." First RSI/ISM International Conference on Robotics and Mechatronics ICRoM. 2013. 38-42.

Toreyin, 2013 Toreyin, B. U. "Fire detection algorithms using multimodal signal and image analysis." 2009.

Verstock et al., 2012 Verstockt S., Poppe C., Van Hoecke S., Hollemeersch C., Merci B., Sette B., Lambert P., Van de Walle R. "Silhouette-based multi-sensor smoke detection." Machine Vision and Applications 23, no. 6 2012: 1243-1262.

Verstock et al., 2010 Verstockt S., Vanoosthuyse A., Van Hoecke S., Lambert P., Van De Walle R. "Multi-sensor Fire Detection by Fusing Visual and Non-visual Flame Features." Proceedings of the 4th International Conference on Image and Signal Processing. 2010. 333-341.

Vipin, 2012 Vipin, V. "Image Processing Based Forest Fire Detection." Int. Journal of Emerging Technology and Advanced Engineering 2, no. 2012. 